EPJ Web of Conferences 106, 02001 (2016)

DOI: $10.1051 /$ epjconf/201610602001

(C) Owned by the authors, published by EDP Sciences, 2016

\title{
In-Vessel and Ex-Vessel Neutron Dosimetry Programs in Korea
}

\author{
Choon Sung Yoo ${ }^{1, a}$, Byoung Chul Kim², Arnold H. Fero ${ }^{3}$, and Stanwood L. Anderson ${ }^{3}$ \\ ${ }^{1}$ Korea Atomic Energy Research Institute, 989-111 Daedeok-daero, Yuseung, Daejeon, Korea \\ ${ }^{2}$ Korea Reactor Integrity Surveillance Technology, 168 Gajeong-ro, Yuseung, Daejeon, Korea \\ ${ }^{3}$ Westinghouse Electric Company LLC, 1000 Westinghouse Drive, Cranberry Township, \\ Pennsylvania 16066-5228, USA
}

\begin{abstract}
In Korea, 20 PWRs are operating and 4 more PWRs are under construction. The in-vessel neutron dosimetry programs have been designed and implemented since each plant began operation. In addition to the in-vessel dosimetry program, ex-vessel neutron dosimetry systems have been installed for 16 PWRs. The objective of this paper is to describe the in-vessel and ex-vessel neutron dosimetry program of the PWRs in Korea and to compare in-vessel and ex-vessel dosimetry evaluation results. For this purpose plant and cycle specific forward neutron transport calculations and dosimetry measurement evaluations were carried out according to Regulatory Guide 1.190. Comparisons between the calculations and measurements were also performed for the reaction rates of each dosimetry sensor and the results show good agreement.
\end{abstract}

\section{Introduction}

In Korea, 20 PWRs are operating and 4 more PWRs are under construction. Of the PWRs, two are Westinghouse-design two-loop plants, four are Westinghouse-design three-loop plants, two are Framatome-design three-loop plants, and the others are Korea Standard Nuclear Power Plant (KSNP), similar to CE-design plants.

The USA Code of Federal Regulations, Title 10, Part 50, Appendix H, requires that neutron dosimetry be present to monitor the reactor vessel throughout plant life and that material specimens be used to measure damage associated with the end-of-life fast neutron exposure of the reactor vessel [1]. The Korea Institute of Nuclear Safety (KINS) has similar requirements in Korea. Therefore, the in-vessel neutron dosimetry programs have been designed and implemented since each plant began operation. The in-vessel dosimetry program consists of six surveillance capsules located between the core and the reactor vessel in the downcomer region near the reactor core or near the reactor vessel wall. These six in-vessel surveillance capsules are programmed to be withdrawn and analyzed periodically in accordance with the surveillance program. When all six in-vessel surveillance capsules have been

\footnotetext{
${ }^{\mathrm{a}}$ Corresponding author: csyoo@kaeri.re.kr
}

This is an Open Access article distributed under the terms of the Creative Commons Attribution License 2.0, which permits unrestricted use, distribution, and reproduction in any medium, provided the original work is properly cited. 


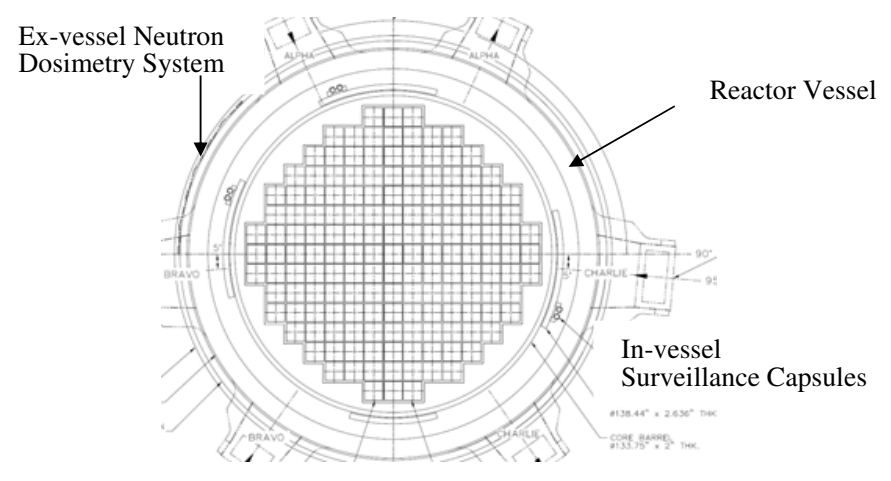

Figure 1. Surveillance Capsule Locations of 3-Loop PWRs.

withdrawn, there is no longer a neutron dosimetry system to monitor the neutron exposure of the reactor vessel. Thus it is necessary to install an ex-vessel neutron dosimetry system. In addition, when the periods between the scheduled capsule withdrawals are too long, it is also necessary to install an exvessel neutron dosimetry system in order to obtain timely neutron fluence data. In Korea, ex-vessel neutron dosimetry systems have been installed for 16 PWRs in the reactor cavity annulus in order to characterize the neutron energy spectrum variations axially and azimuthally over the beltine region of the reactor vessel. The ex-vessel neutron dosimetry system consists of steel chains and capsules, the chains were used to provide measurements of fluence variation and the capsules were used to provide details of neutron spectrum.

\section{In-vessel Neutron Dosimetry Program}

Each operating PWR of Korea has a reactor vessel surveillance program that consists of six surveillance capsules located between the core and the reactor vessel in the downcomer region near the reactor core or near the reactor vessel wall.

\subsection{Westinghouse-design and Framatome-design 3-Loop Plants}

The surveillance capsules of Westinghouse-design and Framatome-design 3-loop plants are attached at the neutron pad which is near the core barrel. Figure 1 shows the six surveillance capsule locations for the typical 3-loop plants. The clockwise azimuthal angles of the six capsules are $107^{\circ}, 110^{\circ}, 287^{\circ}, 290^{\circ}$, $340^{\circ}$, and $343^{\circ}$ from plant north $\left(0^{\circ}\right)$. The capsules contain reactor vessel material specimens including weld metal and heat-affected zone metal. The capsules also contain dosimeters including $\mathrm{Ni}, \mathrm{Cu}, \mathrm{Fe}$, $\mathrm{Co}-\mathrm{Al}, \mathrm{Cd}$ shielded $\mathrm{Co}-\mathrm{Al}, \mathrm{Cd}$ shielded ${ }^{238} \mathrm{U}$ and ${ }^{237} \mathrm{~Np}$.

Figure 1 also shows the location of the ex-vessel neutron dosimetry system which is installed in the annular space between the reactor vessel reflective insulation and the concrete primary biological shield at clockwise azimuthal angles between $270^{\circ}$ and $315^{\circ}$.

The maximum flux on the vessel inner radius occurs on the cardinal axis of the plant which are 0 , 90, 180, and 270 degrees of plant azimuthal angle. The lead factors of the capsules are highly dependent on the capsule location and slightly dependent on the core power distributions. The lead factors of the 3-loop plants are mostly between 2.9 and 3.5 which are greatly higher than those of CE-design KSNPs of which lead factors are less than 1.5. The typical surveillance capsule withdrawal schedules in terms of effective full power years for the 3-loop plants are listed in Table 1. 


\title{
$15^{\text {th }}$ ISRD
}

Table 1. In-vessel Surveillance Programs for 3-loop Plants.

\begin{tabular}{|c|c|c|c|c|}
\hline \multirow{2}{*}{ Capsule } & \multicolumn{2}{|c|}{ Westinghouse-design } & \multicolumn{2}{c|}{ Framatome-design } \\
\cline { 2 - 5 } & $\begin{array}{c}\text { Install } \\
\text { [EFPY] }\end{array}$ & $\begin{array}{c}\text { Withdrawal } \\
\text { [EFPY] }\end{array}$ & $\begin{array}{c}\text { Install } \\
\text { [EFPY] }\end{array}$ & $\begin{array}{c}\text { Withdrawal } \\
\text { [EFPY] }\end{array}$ \\
\hline 1st & 0 & 1 & 0 & 3 \\
\hline 2nd & 0 & 3 & 0 & 5 \\
\hline 3rd & 0 & 7 & 0 & 8 \\
\hline 4th & 0 & 12 & 0 & 11 \\
\hline 5th & 0 & 15 & 12 & being irradiated \\
\hline 6th & 0 & 15 (standby) & 12 & being irradiated \\
\hline
\end{tabular}

For each Westinghouse-design 3-loop plant a total 6 capsules were installed before initial fuel loading, and then, 5 capsules have been withdrawn and tested according to the surveillance program. The fast neutron $(\mathrm{E}>1 \mathrm{MeV})$ fluence of the 5 th capsule is about $5 \sim 6 \times 10^{19} \mathrm{n} / \mathrm{cm}^{2}$, which is about 1.5 times of the end-of-life (40 years) fluence for vessel inner radius. The 6th capsule has been withdrawn and stored in the spent fuel pool without material testing. Because of the high lead factor of this capsule, the vessel material samples in the capsule may, if left in the reactor, receive neutron damage well beyond any projected end-of-life condition. This issue is particularly important for those plants planning for license renewal. The GALL report [2], Section XI.M31 Reactor Vessel Surveillance, provides the following guidance for surveillance capsule management.

\begin{abstract}
A plant with a surveillance program containing capsules with projected fast neutron fluence exceeding a 60-year fluence at the end of 40 years, i.e. a lead factor greater than 1.5, should remove the capsules when they reach the 60-year exposure. One of these capsules should be tested to meet the requirements of ASTM E185 and the remaining capsules should be placed in storage without material testing. Subsequently, an alternative dosimetry program will need to be instituted to monitor reactor vessel neutron exposure through the license renewal period.
\end{abstract}

The NRC has recognized the importance of preserving the material specimens within the surveillance capsules. Any capsules that are to be left in the reactor vessel are to provide meaningful metallurgical data. For a high lead factor plant, if the remaining surveillance capsules are left in place, the material specimens will be irradiated well beyond the predicted end-of-life fast neutron exposure. With passive neutron sensors located in the reactor cavity the neutron exposure of the reactor vessel can be continuously monitored throughout plant life, as required by Appendix H [1], and the surveillance capsules can be removed and stored on site thus preserving this critical, irreplaceable material for future use.

For each Framatome-design 3-loop plant 4 surveillance capsules (1st through 4th) have been installed before initial fuel loading, and then, all 4 capsules have been withdrawn and tested. After withdrawal of 4 capsules, 2 new capsules (5th and 6th) have been installed and they are being irradiated in order to receive 60-year fast neutron exposure for license renewal. The irradiation period is estimated more than 15 years for obtaining 60-year exposure, and it was necessary to institute the ex-vessel neutron dosimetry system in order to monitor vessel exposure continuously throughout plant life.

\subsection{CE-design KSNP Plants}

The surveillance capsules of CE-design KSNP plants are placed in capsule holders that are attached to the reactor vessel cladding. Figure 2 shows a brief drawing for the capsule locations. The clockwise azimuthal angles of the 6 capsules are $263^{\circ}, 277^{\circ}, 284^{\circ}, 83^{\circ}, 97^{\circ}$, and $104^{\circ}$ from plant north $\left(180^{\circ}\right)$. Among the total 6 surveillance capsules, 3 capsules (1st through 3rd) are to be withdrawn and tested during the 40-year plant life and the remaining 3 capsules (4th through 6th) are standby. The 3 standby capsules are provided in the event they are needed to monitor the effect of a major core change or 


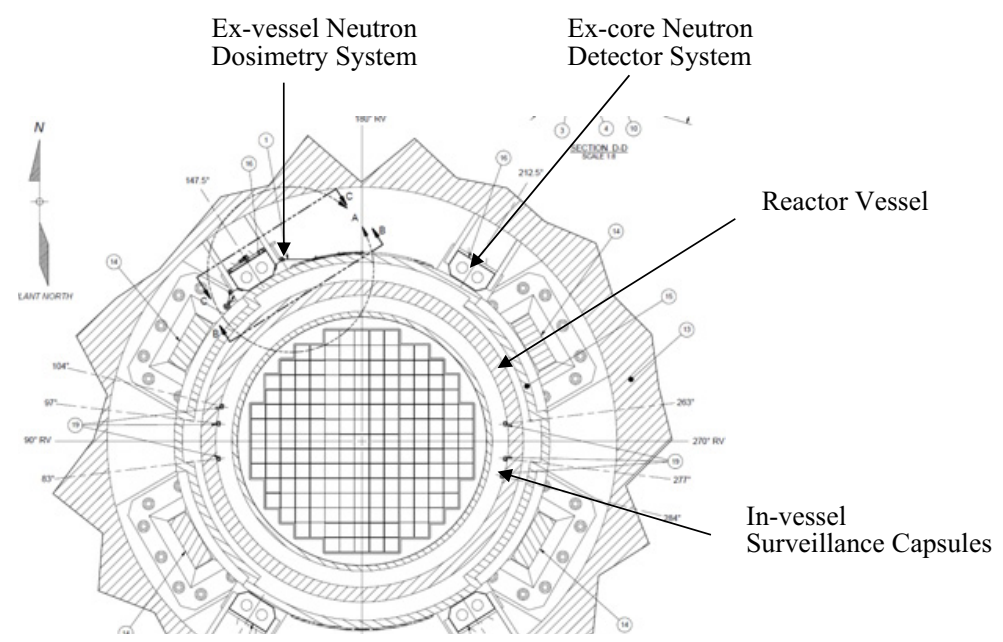

Figure 2. Surveillance Capsule Locations of KSNP Plants.

Table 2. In-vessel Surveillance Programs for CE-design KSNP Plants.

\begin{tabular}{|c|c|c|}
\hline \multirow{2}{*}{ Capsule } & \multicolumn{2}{|c|}{ CE-design KSNP Plants } \\
\cline { 2 - 3 } & $\begin{array}{c}\text { Install } \\
\text { [EFPY] }\end{array}$ & $\begin{array}{c}\text { Withdrawal } \\
\text { [EFPY] }\end{array}$ \\
\hline 1st & 0 & $6-8$ \\
\hline 2nd & 0 & $14-16$ \\
\hline 3rd & 0 & $22-24$ \\
\hline 4th & 0 & Standby \\
\hline 5th & 0 & Standby \\
\hline 6th & 0 & Standby \\
\hline
\end{tabular}

annealing of the vessel, or to provide supplemental toughness data for evaluating a flaw in the beltline. Table 2 shows the installation and withdrawal schedules in terms of effective full power years of in-vessel surveillance programs for CE-design KSNP plants.

The capsules contain reactor vessel material specimens including weld metal and heat-affected zone metal. The capsules also contain dosimeters including $\mathrm{Ni}, \mathrm{Cu}, \mathrm{Fe}, \mathrm{Ti}, \mathrm{Nb},{ }^{238} \mathrm{U}, \mathrm{Co}-\mathrm{Al}$, and $\mathrm{Cd}$ shielded $\mathrm{Co}-\mathrm{Al}$, and $\mathrm{Cd}$ shielded ${ }^{238} \mathrm{U}$, however the capsules does not contain ${ }^{237} \mathrm{~Np}$.

\section{Ex-vessel Neutron Dosimetry Program}

As discussed in the previous section, the ex-vessel neutron dosimetry programs have been designed and instituted for 16 PWRs in Korea. The purpose of the system is to provide a mechanism for the long term monitoring of the neutron exposure of those portions of the reactor vessel that may experience radiation induced increases in reference nil ductility transition temperature $\left(\mathrm{RT}_{\mathrm{NDT}}\right)$ over the nuclear power plant lifetime. The design of the dosimetry support system and the gradient chains and chain stops ensures correct axial and azimuthal placement of the dosimetry relative to well-known reactor features [3].

When used in conjunction with dosimetry from in-vessel surveillance capsules and with the results of neutron transport calculations, the ex-vessel neutron dosimetry measurements allow the projection of embrittlement gradients through the reactor vessel wall with a minimum uncertainty. The neutron sensors contained in the in-vessel capsules provide a measurement at a single location, therefore, they cannot provide information regarding the azimuthal, axial, and radial gradients of neutron exposure 


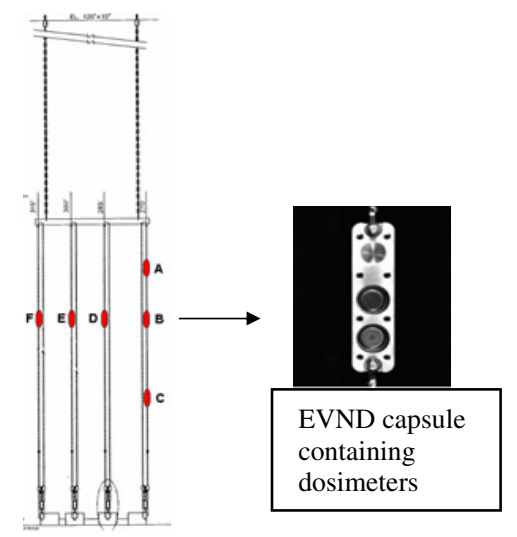

Figure 3. Ex-vessel neutron Dosimetry System for 3-Loop Plants.

within the reactor vessel. Furthermore, data from in-vessel capsules are, by design, obtained at rather infrequent intervals; and surveillance measurement locations may not be in proximity to critical areas on the reactor vessel.

An ex-vessel neutron dosimetry program can also provide additional data to license renewal application. As a comprehensive system to characterize the neutron exposure of the reactor vessel, it has the flexibility to:

- Monitor important azimuthal and axial exposure gradients over the entire beltline region of reactor vessel and provide measurements in proximity to critical areas on the reactor vessel,

- Provide long term monitoring that permits continuous evaluation of the effect of changes in reactor operation and changing fuel management schemes on the reactor vessel exposure, and

- Minimize the uncertainty in reactor vessel exposure projections using a combination of measurements and analytical predictions.

To achieve the goals of the ex-vessel neutron dosimetry program, two types of measurements are made. Comprehensive sensor sets including radiometric monitors (RM) are employed at discrete locations within the reactor cavity. In addition, stainless steel gradient chains are used in conjunction with the encapsulated dosimeters to complete the mapping of the neutron environment between the discrete locations chosen for spectrum determinations.

\subsection{Westinghouse-design and Framatome-design 3-Loop Plants}

In choosing sensor set locations for ex-vessel neutron dosimetry program, advantage is taken of the octant symmetry typical of pressurized water reactors. Spectrum measurements are concentrated to obtain azimuthal flux distributions in a single 45 degree sector. Placement of the discrete sensor sets is such that spectrum determinations are made at various locations (typically $0,15,30$, and 45 degrees) on the midplane of the active core to measure the spectrum changes caused by the varying amounts of water located between the core and the reactor vessel. For the 0 degree location, additional sensor sets are positioned opposite the top and bottom of the reactor active core. Here the intent is to measure axial variations in neutron spectrum over the core height, particularly near the top of the fuel where there is back scattering of neutrons from primary loop nozzles and reactor vessel. Figure 3 shows the typical description of the ex-vessel neutron dosimetry systems for the 3-loop plants in Korea. 


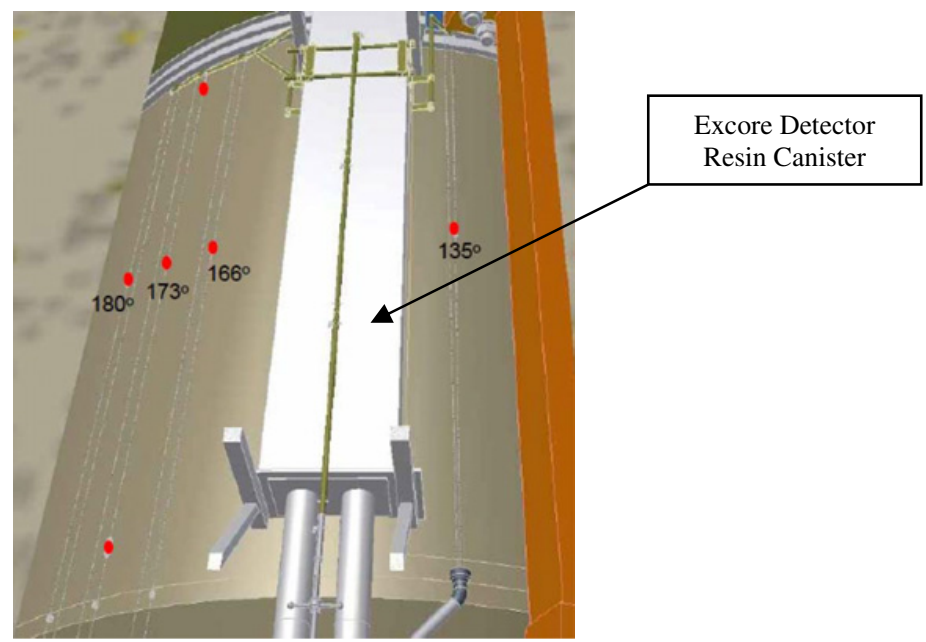

Figure 4. Ex-vessel neutron Dosimetry System for CE-design KSNP Plants.

The ex-vessel neutron dosimetry programs for 3-loop plants have been instituted since 2003. To date the sensor sets were withdrawn and evaluated 3 or 4 times for each plant and the dosimetry measurements were compared to the in-vessel dosimetry measurements and the results are discussed in Sect. 4.

\subsection{CE-design KSNP Plants}

For CE-design KSNP plants, the ex-vessel neutron dosimetry is located at the octant-equivalent angles of $0,7,14$, and 45 degrees which are 180,173,166, and 135 degrees of plant azimuthal angle, respectively. The reasons for that positioning are to locate dosimetry at angles that correspond to the angles of the in-vessel surveillance capsules (octant-equivalent angles of 7 and 14 degrees) and to avoid having dosimetry located directly behind the ex-core detector resin canister that is centered at 147.5 degrees as it would cause significant perturbation of the measurement. The dosimetry sensor sets and the gradient chains are all the same as the 3-loop plants discussed in the previous section.

The support frame is installed around an ex-core detector resin canister which provides both azimuthal positioning for the dosimetry and provides support for the system [4]. Figure 4 shows the position of the ex-vessel neutron dosimetry system installed in CE-design KSNP plants in relation to the excore detector resin canister. The ex-vessel neutron dosimetry programs for CE-design KSNP plants have been instituted since 2008. To date the sensor sets were withdrawn and evaluated 2 or 3 times for each plant and the dosimetry measurements were compared to the in-vessel dosimetry measurements and the results are discussed in the next section.

\section{Transport Calculation and Dosimetry Evaluation}

Plant and cycle specific forward neutron transport calculations were carried out by using the threedimensional flux synthesis technique described in Regulatory Guide 1.190 as below [5]:

$$
\phi(r, \theta, z)=\phi(r, \theta) \bullet \frac{\phi(r, z)}{\phi(r)}
$$


Table 3. Ratios of Measurement-to-Calculation Reaction Rates of In-vessel Capsules for 3-loop Plants.

\begin{tabular}{|c|c|c|c|c|c|c|}
\hline \multirow[b]{2}{*}{$\begin{array}{l}\text { Plant } \\
\text { Types }\end{array}$} & \multirow[b]{2}{*}{ Capsule } & \multicolumn{5}{|c|}{ Measurement-to-Calculation Reaction Rate Ratio (M/C) } \\
\hline & & $\begin{array}{c}{ }^{63} \mathrm{Cu}(\mathrm{n}, \alpha) \\
{ }^{60} \mathrm{Co}\end{array}$ & $\begin{array}{c}{ }^{54} \mathrm{Fe}(\mathrm{n}, \mathrm{p}) \\
{ }^{54} \mathrm{Mn}\end{array}$ & $\begin{array}{c}{ }^{58} \mathrm{Ni}(\mathrm{n}, \mathrm{p}) \\
{ }^{58} \mathrm{Co}\end{array}$ & $\begin{array}{c}{ }^{238} \mathrm{U}(\mathrm{n}, \mathrm{f}) \\
{ }^{137} \mathrm{Cs}\end{array}$ & $\begin{array}{c}{ }^{237} \mathrm{~Np}(\mathrm{n}, \mathrm{f}) \\
{ }^{137} \mathrm{Cs}\end{array}$ \\
\hline \multirow{6}{*}{$\begin{array}{c}\text { WH } \\
\text { 3-loop } \\
\text { (HB-1) }\end{array}$} & 1 st & 1.03 & 0.95 & 1.00 & - & - \\
\hline & 2nd & 1.04 & 0.92 & 0.96 & - & - \\
\hline & 3 rd & 1.05 & 0.93 & 0.90 & - & - \\
\hline & 4th & 1.03 & 0.91 & 0.89 & 0.84 & 0.94 \\
\hline & 5 th & 1.02 & 0.91 & 0.93 & 0.95 & 0.92 \\
\hline & Avg. & 1.03 & 0.92 & 0.94 & 0.90 & 0.93 \\
\hline \multirow{5}{*}{$\begin{array}{c}\text { Framatome } \\
\text { 3-loop } \\
\text { (HU-2) }\end{array}$} & $1 \mathrm{st}$ & 1.12 & 1.05 & 1.04 & - & - \\
\hline & 2nd & 1.09 & 0.89 & - & - & - \\
\hline & 3 rd & 1.10 & 0.90 & - & - & - \\
\hline & 4th & 1.11 & 0.90 & 0.93 & - & - \\
\hline & Avg. & 1.11 & 0.94 & 0.99 & - & - \\
\hline
\end{tabular}

where $\phi(r, \theta, z)$ is the synthesized three-dimensional neutron flux distribution, $\phi(r, \theta)$ is the transport solution in an R- $\theta$ geometry, $\phi(r, z)$ is the two-dimensional solution for a cylindrical reactor model using the actual power distribution, and $\phi(r)$ is the one-dimensional solution for a cylindrical reactor model using the same source per unit height as that used in the R- $\theta$ two-dimensional calculation. For the analysis, all the transport calculations were carried out by using the DORT 3.1 discrete ordinate code [6] and the BUGLE-96 cross-section library [7]. The BUGLE-96 library provides a 67 group coupled neutron-gamma ray cross-section data set produced specifically for a light water reactor application. In these analyses, anisotropic scattering was treated with a $\mathrm{P}_{5}$ Legendre expansion and the angular discretization was modeled with an $\mathrm{S}_{16}$ order of angular quadrature. The SORCERY [8] computer code was used to prepare a fixed distributed source for DORT transport calculations. The fuel assembly specific enrichment and burnup data were used to generate the spatially dependent neutron source throughout the reactor core. This source description included a spatial variation of the isotopic dependent ${ }^{235} \mathrm{U},{ }^{238} \mathrm{U},{ }^{239} \mathrm{Pu},{ }^{240} \mathrm{Pu},{ }^{241} \mathrm{Pu}$, and $\left.{ }^{242} \mathrm{Pu}\right)$ fission spectra, the neutron emission rate per fission, and the energy release per fission based on the burnup history of individual fuel assemblies. The radial core burnup and axial core power distributions were taken from the appropriate Nuclear Design Reports for the analyzed operating cycles.

The sensor reaction rates are derived from the measured specific activities and plant specific operating history. Using SNLRML [9] dosimetry cross section and the neutron spectrum derived from transport calculations for the dosimetry location, calculated sensor reaction rates are also determined. A least-squares adjustment method [10] combining dosimetry measurement data with the corresponding neutron transport calculations is used to establish a best estimate spectrum and an estimate of the applicable uncertainties at the locations of measurement.

\section{Results and Discussions}

Table 3 shows the direct comparisons of measurements and pure calculations (prior to spectrum adjustment) for the in-vessel dosimeter reaction rates $(\mathrm{M} / \mathrm{C})$ of 3-loop plants. As shown in this table, $\mathrm{M} / \mathrm{C}$ values are very close to 1.0 and satisfy the $\pm 20 \%$ acceptance criterion described in Regulatory Guide 1.190 [5].

Table 4 shows the summary of the least squares adjustments for in-vessel and ex-vessel dosimetry programs for typical 3-loop and KSNP plants. In this Table "BE" means best estimated neutron spectrum $(\mathrm{E}>1 \mathrm{MeV}$ ) adjusted by the least squares adjustments and " $\mathrm{C}$ " means pure calculated neutron spectrum $(\mathrm{E}>1 \mathrm{MeV})$ by transport calculation. For the case of the ex-vessel dosimetry program, the BE/C values 
Table 4. Summary of Least Squares Evaluations for Korea PWRs.

\begin{tabular}{|c|c|c|c|c|}
\hline \multirow{2}{*}{$\begin{array}{l}\text { Plant } \\
\text { Types }\end{array}$} & \multirow{2}{*}{$\begin{array}{l}\text { Withdrawal } \\
\text { Number }\end{array}$} & \multicolumn{3}{|c|}{ Best Estimated-to-Calculated Spectrum Ratio (BE/C) } \\
\hline & & In-vessel & Ex-vessel & Overall \\
\hline \multirow{6}{*}{$\begin{array}{c}\text { WH } \\
\text { 3-loop } \\
\text { (HB-1) }\end{array}$} & $1 \mathrm{st}$ & 0.99 & 0.92 & - \\
\hline & 2nd & 0.94 & 0.94 & - \\
\hline & 3rd & 0.91 & 0.89 & - \\
\hline & 4th & 0.89 & 0.94 & - \\
\hline & 5 th & 0.93 & - & - \\
\hline & Avg. & 0.93 & 0.92 & 0.93 \\
\hline \multirow{5}{*}{$\begin{array}{c}\text { Framatome } \\
\text { 3-loop } \\
\text { (HU-2) }\end{array}$} & $1 \mathrm{st}$ & 1.03 & 0.85 & - \\
\hline & 2nd & 0.90 & 0.86 & - \\
\hline & 3rd & 0.91 & 0.84 & - \\
\hline & 4th & 0.89 & - & - \\
\hline & Avg. & 0.93 & 0.85 & 0.89 \\
\hline \multirow{3}{*}{$\begin{array}{l}\text { KSNP } \\
(\mathrm{HB}-3)\end{array}$} & $1 \mathrm{st}$ & 0.96 & 1.08 & - \\
\hline & 2nd & 1.01 & 1.11 & - \\
\hline & Avg. & 0.98 & 1.09 & 1.04 \\
\hline
\end{tabular}

listed in the table are the average of $\mathrm{BE} / \mathrm{C}$ of 4 midplane capsules. As shown in this table, the BE/C ratios of in-vessel and ex-vessel dosimetry programs are in very good agreement with each other.

In this paper in-vessel and ex-vessel neutron dosimetry programs were evaluated and compared to the neutron transport calculations. The results show good agreement between measurement and calculation for the reaction rate of each sensor. In conclusion, these systems satisfy the requirements of Korea Regulatory Institute and can be used in the monitoring of the fast neutron exposure for the reactor vessel embrittlement assessments.

\section{References}

[1] 10 CFR 50, Appendix H, "Reactor Vessel Material Surveillance Program Requirements," USNRC

[2] NUREG-1801, Rev. 1, "Generic Aging Lessons Learned (GALL) Report," September 2005

[3] B. C. Kim, C. S. Yoo, S. L. Anderson, A. H. Feo, and Charles C. Kim, "The Role of ExVessel Neutron Dosimetry in Reactor Vessel Surveillance in South Korea," 13th International Symposium on Reactor Dosimetry (ISRD-13), Hotel Akersloot, The Netherlands, May 25-30, 2008

[4] J. L. Duo, J. Chen, J. A. Kulesza, A. H. Fero, C. S. Yoo, and B. C. Kim, "Korean Standard Nuclear Power Plant Ex-vessel Neutron Dosimetry Program Ulchin 4," 14th International Symposium on Reactor Dosimetry (ISRD-14), Mt. Washington Resort, Bretton Woods, NH, USA, May 22-27, 2011

[5] US NRC Regulatory Guide 1.190, "Calculational and Dosimetry Methods for Determining Pressure Vessel Neutron Fluence," March 2001

[6] RSICC Computer Code Collection CCC-650, "DOORS 3.2, One-, Two, and Three-Dimensional Discrete Ordinates Neutron/Photon Transport Code System," Oak Ridge, TN, 1998

[7] RSIC Data Library Collection DLC-185, "BUGLE-96, Coupled 47 Neutron, 20 Gamma-Ray Group Cross Section Library Derived from ENDF/B-VI for LWR Shielding and Pressure Vessel Dosimetry Applications," Oak Ridge, TN, 1996

[8] Westinghouse Electric Company LLC, “SORCERY User Manual,” December 2001

[9] RSIC Data Library Collection DLC-178, "SNLRML Recommended Dosimetry Cross-Section Compendium," July 1994

[10] S. L. Anderson, "Benchmark Testing of the FERRET Code for Least Squares Evaluation of Light Water Reactor Dosimetry,” Westinghouse WCAP-16083-NP-A, Revision 0, May 2006 